\title{
Ecological Engineering Trench Inspection and Foundation Reinforcement in the New Era
}

\author{
Xiaoyuan Xiong \\ Henan Vocational University of science and technology, Henan,China
}

\begin{abstract}
:
The structure layer of geocell reinforced with macadam, as well as effectiveness and practicality of such a method in foundation reinforcement during work progress of civil engineering is studied in this paper. Basic theory and method about foundation reinforcement structure applied in work process of civil engineering have been studied. Physical model of experimental tank built by loaded plates has been established. Experiments have been conducted on the loaded-plate tank for geocells in different specification and filler in the geocell to determine the relationship between loads at various of structure layers and longitudinal travel. Experimental results showed that structure layer of geocell reinforced with macadam could improve vertical deformation in a better way, whose efficiency became smaller along with weld spacing of geocell getting larger within a certain range. Besides, specification of the filler also imposed effects onto the reinforcement efficiency, where filler with larger particle diameter brought about better reinforcement effects. The experimental results demonstrated rationality and effectiveness of structure layer of geocell reinforced with macadam and provided staff members responsible for civil engineering construction with reference on selecting the foundation reinforcement scheme.
\end{abstract}

Keywords: Ecological Engineering, Trench Inspection, Foundation, Reinforcement, Data Fusion

\section{INTRODUCTION}

In recent years, with the rapid development of foundation treatment technology, various new processes, new technologies and new materials emerge in endlessly. However, in a relatively small area, it is still rare to use drainage consolidation method, vibroflotation method, Vibroflotation Gravel Pile method [1-2], dynamic compaction method (including common compaction, ordinary energy dynamic compaction, large energy dynamic compaction), dynamic compaction broken stone column method, vibration rolling method and other methods for foundation treatment engineering [3].

The total area of a container yard is $789000 \mathrm{~m}^{2}$. The formation and boundary conditions of the land area are very complex [4]. The formation of the land area includes: blasting, backfilling with rock, backfilling with silty fine sand on the original muddy natural foundation, gravel mixed with silt, etc. the content of fine particles in the blown sand layer near the land boundary is very high [5-7]. As the superstructure of the project is a container yard with large concrete slab structure, the requirements for foundation bearing capacity and settlement are very high. 


\section{LAND SITUATION}

\subsection{Geological conditions of natural foundation}

The natural foundation is mainly distributed in II 1 grayish yellow silty clay with silt, III 1-1 grayish yellow grey silt, III 1-2 grayish yellow grey mucky soil and III 2 grayish yellow grey mucky silty clay. The distribution characteristics of soft soil layer are as follows: in the area near the shore, the thickness of soft soil layer is relatively small, especially in the area near the proposed wharf, with a thickness of 10.0-17.0 M. the specific distribution is muddy soft clay layer (including layer I-III), and a small amount of silty fine sand lens is developed in some sections. Under layer III (layer II in some shallow bedrock areas), there is layer IV (layer V in some parts) with relatively good engineering geological properties, which is plastic and hard; in the coastal areas, the weathering layer of bedrock IV is basically exposed.

\subsection{Geological condition of backfill layer}

There are three main forms of land formation: reclamation of fine sand to form land, backfilling of rock to form land and mountain to form land. Among them, the total amount of sand blowing is about 5 million $\mathrm{m}^{3}$, and the thickness is 1-25 $\mathrm{m}$, which is in loose state; the land area formed by backfilled Kaishan stone is about $360000 \mathrm{~m}^{2}$, of which about $60000 \mathrm{~m}^{2}$ is the original silt promoting dike, and the area is Kaishan stone mixed with silt foundation. The rest of the area is formed by mountain opening.

\section{REQUIREMENTS FOR FOUNDATION REINFORCEMENT EFFECT}

1) The bearing capacity of the foundation after reinforcement and leveling is more than $150 \mathrm{kPa}$.

2) Effective reinforcement depth [8].

(1) The reinforcement depth of vibroflotation method: in the area where the thickness of hydraulic fill sand is more than $15 \mathrm{~m}$, the bottom elevation of vibroflotation method is $-8.0 \mathrm{~m}$; in the area where the thickness of hydraulic fill sand is not more than $15 \mathrm{~m}$. Control by vibroflotation to mud surface;

(2) The reinforcement depth of dynamic compaction area shall not be less than $8 \mathrm{~m}$;

(3) The reinforcement depth of dynamic compaction broken stone column area is not less than 8-10m;

3) The number of standard penetrations in vibroflotation reinforcement area is $\mathrm{N}_{635} \geqslant 15$.

\section{REINFORCEMENT METHOD OF NATURAL FOUNDATION}

\subsection{Selection of reinforcement methods}

1) Drainage method

Drainage consolidation method is to set up plastic drainage board or sand well in natural soft soil to form vertical drainage channel, and produce additional stress by applying external load to make natural soil consolidated under the action of external load (mainly manifested as dissipation of excess pore water pressure and rearrangement of particles), so as to achieve effective reinforcement effect. According to the loading mode, drainage consolidation method can be divided into surcharge preloading method, vacuum preloading method and vacuum preloading combined surcharge method.

Surcharge preloading method is one of the common methods to treat large area soft soil foundation in 
port engineering. The reinforcement depth is large, the reinforcement effect is good, the construction technology is relatively simple, the cost is low, and the reasonable arrangement can generally meet the requirements of the construction period. But this method needs a lot of earthwork, and earthwork balance is the key of this method [9].

In vacuum preloading method, there is no need to pile up stonework, and the air under the vacuum membrane is extracted by vacuum pump, so that the atmospheric pressure difference is formed inside and outside the membrane, so as to produce a certain amount of additional stress on the soft soil [10]. And because it produces negative pressure, the total stress of soil does not increase with the increase of effective stress, so it will not cause shear failure of soil, and there is no need for graded loading, which can greatly shorten the construction period. However, the maximum additional stress produced by vacuum preloading method can only reach about $80 \mathrm{kPa}$. The depth of vacuum transmission is also limited, so the applicable conditions are limited. For the case that the soft soil layer is deep, and the soft soil layer is covered with a considerable thickness of hydraulic fill sand, the Dingyi is not applicable, so the vacuum preloading method can not be used in this project.

2) Desilting and replacement method

Desilting replacement method is to use large-scale modern ship machinery equipment to excavate all or part of the soft soil layer in the original natural foundation, and then backfill the rock or sand with good engineering performance. This method is the most direct and reliable reinforcement method, so it is often used in the projects with strict settlement requirements in developed countries and regions. However, the dredging method not only produces a large amount of abandoned dredged soil, but also needs to backfill a large amount of backfill to form land area, which will greatly increase the project cost and prolong the construction period. For this project, the deepest elevation of natural soft soil floor is - $44 \mathrm{~m}$, so the desilting method is not suitable for this project.

3) Cement mixing pile method

Cement mixing pile method is to use cement as curing agent to combine soft clay with curing agent by deep mixing machine. By using a series of physical and chemical reactions between curing agent and soft clay, the hard layer of soft soil can be turned into a high-quality foundation with integrity, water stability and certain strength. This method has been developed from land construction to water construction, and its advantage is that it can quickly improve the bearing capacity and deformation modulus of reinforced soil. However, the reinforcement depth of this method is generally less than $20 \mathrm{~m}$, the speed of water construction is slow, and the engineering quantity is large, the cost is high, so it is not suitable for this project.

According to the above analysis on the advantages and disadvantages of natural stratum reinforcement methods, combined with the geological conditions and existing construction conditions of the project, it is considered that the most economical and effective natural foundation reinforcement method for the project is to set up plastic drainage board as drainage channel, and combine with hydraulic fill sand surcharge preloading for natural foundation reinforcement (Fig. 1). 


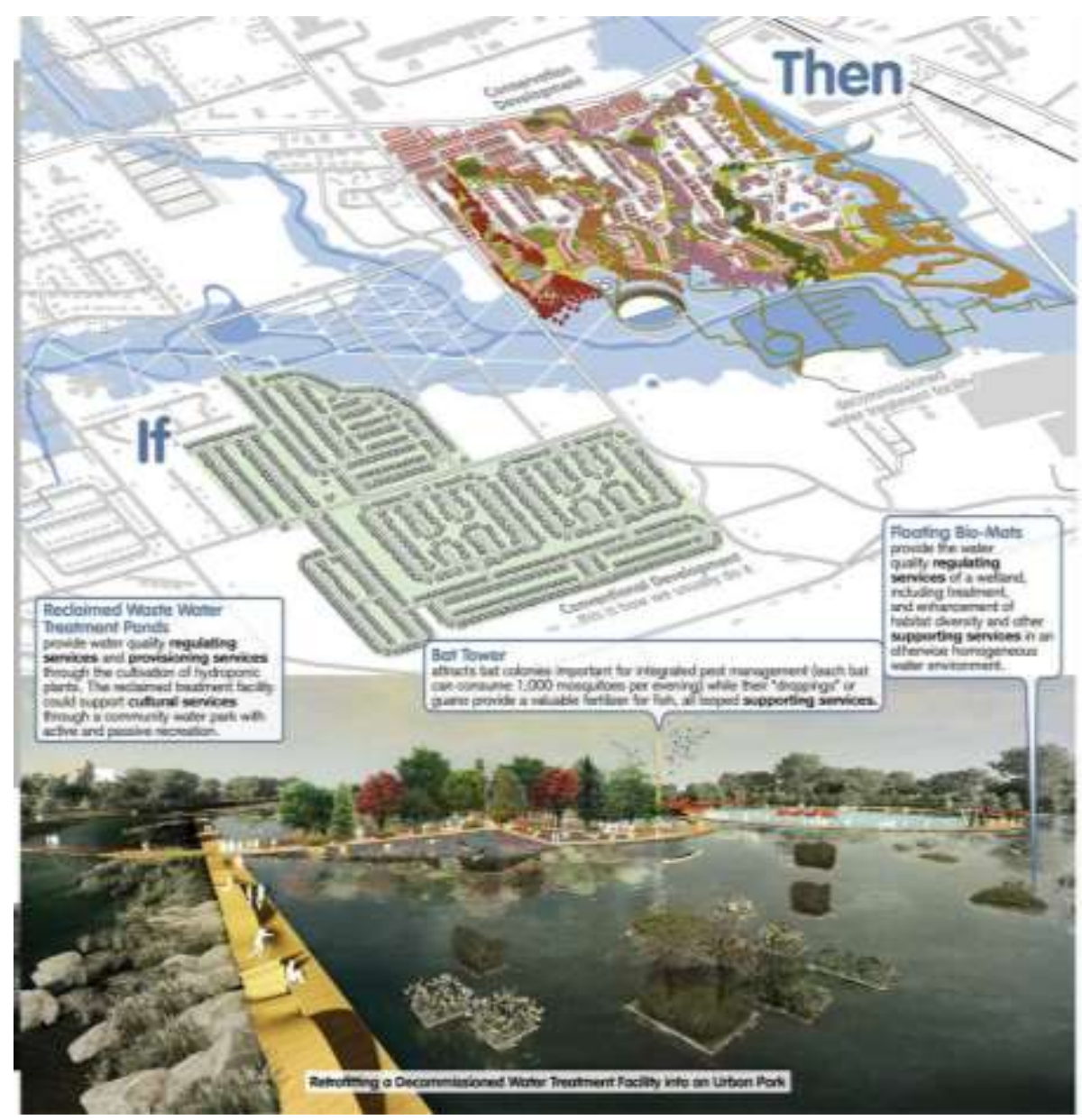

Fig 1: Natural foundation reinforcement plan

\subsection{Main technical parameters and reinforcement effect}

The thickness of the whole backfill layer in the land area of the project is 3-26 m, and the thickness of the natural soft soil layer is $0-18 \mathrm{~m}$. Under the action of large area backfill and service load, the estimated settlement of soft soil is $0.4 \sim 2.98 \mathrm{~m}$. The post construction settlement is estimated to be $0.34-2.59 \mathrm{~m}$ without reinforcement. The distance between the plastic drainage boards is 1.1-1.2 $\mathrm{m}$. the E-type plastic drainage boards are used and arranged in a square shape. The depth is required to penetrate the soft soil layer. According to the overall construction arrangement, some areas adopt the water plug-in technology, and some areas adopt the land plug-in technology. The stacking height of plastic raft on water is $+9.5 \mathrm{~m}$, and that on land is $+11.5 \mathrm{~m}$.

According to the measured data, under the time span of 4-5 months, the consolidation degree of foundation soil is more than $90 \%$, the settlement is $0.8-1.3 \mathrm{~m}$, and the residual settlement can be controlled within $0.3 \mathrm{~m}$.

\section{FOUNDATION REINFORCEMENT METHOD OF BACKFILL LAYER}

In order to improve the strength of the new filling layer and meet the requirements of the upper buildings for the foundation bearing capacity, settlement and residual settlement, different dynamic methods can be used to reinforce the foundation of the backfill layer. 
The total area of foundation treatment is about $600000 \mathrm{~m}^{2}$, including: $173000 \mathrm{~m}^{2}$ reinforced by common compaction combined with vibration rolling method; $187000 \mathrm{~m}^{2}$ reinforced by dynamic compaction combined with vibration rolling method; $164000 \mathrm{~m}^{2}$ reinforced by vibroflotation combined with vibration rolling method; $58700 \mathrm{~m}^{2}$ reinforced by dynamic compaction gravel column; $15500 \mathrm{~m}^{2}$ reinforced by vibration rolling method (Fig. 2).

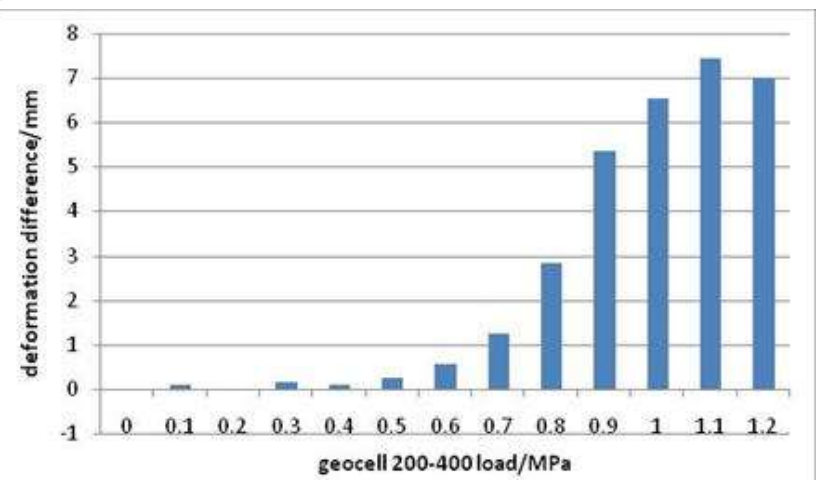

Fig 2: Layout plan of backfill foundation reinforcement

In the first and second stage of the project, the backfilled soil foundation is reinforced with rock and hydraulic fill sand, and the area with thick hydraulic fill sand is reinforced by vibroflotation combined with vibration rolling. The areas near the second stage of the project with thin hydraulic fill sand and the areas without preloading in the first stage of the project are reinforced by vibration rolling and dynamic compaction combined with vibration rolling; the areas with preloading in the first stage are reinforced by common compaction combined with vibration rolling.

\subsection{Vibroflotation combined with vibroflotation}

This method is mainly used to reinforce the reclamation area.

Main technical parameters of vibroflotation combined with vibroflotation

For vibroflotation reinforcement method, a large number of tests have been carried out in the early stage of the project, and mature technical indexes have been obtained. The plane layout of vibration points of vibroflotation method adopts equilateral triangle, the spacing is $3.5 \mathrm{~m}$, the mechanical equipment of vibroflotation method adopts zcq-75, the power is $75 \mathrm{~kW}$, and the vibration points are double point vibration. When the thickness of hydraulic fill sand is more than $15 \mathrm{~m}$ (the top elevation of hydraulic fill sand is +10.0 $\mathrm{m})$, the bottom elevation of vibroflotation is $-7.0 \mathrm{~m}$; when the thickness of hydraulic fill sand is less than $15.0 \mathrm{~m}$ (the top elevation of hydraulic fill sand is $+10.0 \mathrm{~m}$ ), the bottom elevation of vibroflotation is $-7.0 \mathrm{M}$. During vibroflotation construction, if it is found that the clay content of hydraulic fill sand directly affects the vibroflotation compaction effect, coarse-grained materials can be added into the vibroflotation hole (the site gravel, stone slag and purchased medium coarse sand can be considered) to increase the compaction effect.

\section{1) Construction process}

The total area of vibroflotation construction is $163500 \mathrm{~m} 2$. Zhenchong area is divided into Zhenchong 133 districts from east to west. According to the construction sequence from east to West formed in the land area, Zhenchong is constructed from east to west. During vibroflotation construction, due to the high surface elevation $(+9.5 \mathrm{~m})$, the surface dry sand layer is difficult to liquefy. In order to make the sand layer fully saturated with water, a large amount of water is soaked before construction to ensure the vibroflotation effect.

During the construction of Zhenchong 26-33 community, due to a large amount of mud turned out, the 
settlement is small. According to the foundation test results before construction, after detailed analysis of the geological conditions, the construction technology is optimized and adjusted in the design. The method of adding materials and vibroflotation reinforcement is adopted, the medium coarse sand is used as the backfill, and the number of cycles is increased to 4 . In the process of feeding vibroflotation construction, each equipment is equipped with an excavator to fill the hole with medium coarse sand manually to ensure the normal feeding.

5.2 Combined vibration rolling method of conventional compaction and dynamic compaction

This method is mainly used to reinforce the riprap area.

1) Main technical parameters of vibration rolling method combined with conventional compaction and dynamic compaction

1. Common ramming: common ramming once, overlapping ramming, ramming seal overlapping $1 / 3$ hammer bottom diameter, divided into common ramming zone 1 and zone 2, zone 1 each point ramming 5 blows, each blow energy $1200 \mathrm{~kJ}$; zone 2 each point ramming 2 blows, each blow energy $800 \mathrm{~kJ}$.

2. Dynamic compaction: two times of point compaction and one time of common compaction are adopted, the energy of point compaction is $2400 \mathrm{~kJ}$ and $3000 \mathrm{~kJ}$, each point is tamped 10 times, the spacing of point compaction is $6 \mathrm{MX} 3 \mathrm{~m}$, the average tamping settlement of the last two strokes of each point compaction is less than $10 \mathrm{~cm}$; the energy of common compaction is $1200 \mathrm{~kJ}$, each point is tamped 2 times, the diameter of tamping hammer is not less than $2.7 \mathrm{~m}$, and the tamping seal overlaps $1 / 3$ of hammer bottom diameter (Table 1).

TABLE I. Technical parameters of dynamic compaction construction

\begin{tabular}{|c|c|c|c|}
\hline TIMES & $\begin{array}{c}\text { SPACING OF STEP } \\
\text { RAMMER / M }\end{array}$ & $\begin{array}{c}\text { ENERGY PER } \\
\text { STROKE / KJ }\end{array}$ & $\begin{array}{c}\text { TAMPING } \\
\text { NUMBER PER } \\
\text { POINT }\end{array}$ \\
\hline 1 & $6 \times 3$ & $2400(3000)$ & $10-11$ \\
\hline 2 & $6 \times 3$ & $2400(3000)$ & $10-11$ \\
\hline Common rammer & $1 / 3$ Lap rammer & 1200 & 2 \\
\hline
\end{tabular}

2) Construction process of vibration rolling method combined with conventional compaction and dynamic compaction

The total construction area of conventional compaction and dynamic compaction is about $350000 \mathrm{~m}^{2}$. The $50 \mathrm{t}$ crane is mainly used to cooperate with rammers of different tonnage for construction. A total of 13 sets of equipment are organized for operation. When dynamic compaction is carried out in some areas, due to the poor geological conditions of the construction area which was originally a pond and garbage area, the settlement is too large and a large amount of silt overflows during the dynamic compaction process, which affects the quality and safety of dynamic compaction construction. The $3 \mathrm{~m}$ thick silt on the surface of the area is excavated and backfilled with stones. After leveling, the dynamic compaction construction technology is adopted. In the process, the project department strengthens the drainage and the settlement control of the last two blows. The whole construction process of dynamic compaction is basically normal, the interval between two times of point compaction is 3-5 d, the underground water level is controlled below $1.5 \mathrm{~m}$ during dynamic compaction, and there is no abnormal situation in the construction process. The average penetration of the last two blows is less than $10 \mathrm{~cm}$. 


\subsection{Dynamic compaction gravel column method}

This method is a new technology and seldom used in China. In this project, this method is mainly used to reinforce the area of stone mixed with silt within the original silt promoting dike.

1) Typical construction

According to the design requirements and the actual situation of the site, the typical construction area is determined in the dynamic compaction gravel column area II. The specific location is shown in the attached figure, with an area of $30.7 \mathrm{~m} \times 30.7 \mathrm{~m}$, that is, 144 construction points. The specific hole layout is shown in Figure 3 (the shaded part in the figure is the first compaction point, and the blank part is the second compaction point).

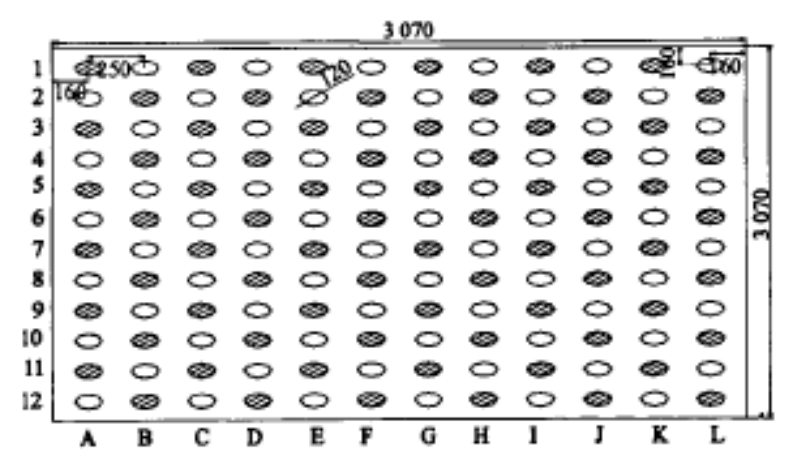

Fig 3: Layout of dynamic compaction points (unit: $\mathrm{cm}$ )

2) Technical parameter

The technical parameters of dynamic compaction are shown in Table 2.

TABLE II. Technical parameters of dynamic compaction

\begin{tabular}{|c|c|c|c|}
\hline TIMES & $\begin{array}{c}\text { SPACING OF STEP } \\
\text { RAMMER / M }\end{array}$ & $\begin{array}{c}\text { ENERGY PER } \\
\text { STROKE / KJ }\end{array}$ & $\begin{array}{c}\text { TAMPING } \\
\text { NUMBER PER } \\
\text { POINT }\end{array}$ \\
\hline 1 & $5.5 \times 2.75$ & 6000 & 40 \\
\hline 2 & $5.5 \times 2.75$ & 6000 & 40 \\
\hline Common rammer & $1 / 3$ Lap rammer & 1200 & 3 \\
\hline
\end{tabular}

\section{CONCLUSION}

In this project, the original natural foundation and backfill foundation are fully treated, and a variety of foundation reinforcement methods are comprehensively used. Some technologies are at the leading level in China.

\section{REFERENCES}

[1] L. Wang, J. Zhou, and M. C. Jia, "Analysis on Influencing Factors of Adjacent Deep Structure Excavation onto Underground Utilities”, vol. 38, no. 10, pp. 65-70, 2008.

[2] Y. L. Zhao, "Simulation Analysis on Non-uniform Settlement of Buildings around Foundation Pit", Journal of Heilongjiang College of Science \& Technology, vol. 1, pp. 45-47, 2007. 
[3] J. Ma, "Experimental Study on Bearing Capacity of Macadam Base Reinforced with Geocell”, M.S. thesis, Xi'an Shaanxi: Changan University, 2013.

[4] H. P. Lai, Y. L. Xie, and X. H. Yang, "Study on Stability of Shallow Layer of Expansive Soil Slop in Xihan Highway”, Journal of Wuhan University of Science \& Technology, vol. 32, no. 1, pp. 29-33, 2010.

[5] Y. Chen, J. Fang, and J. F. Zhao, "Experimental Study on

[6] CF-net Anti- scouring Indoor Model on Side Slope of Highway", Journal of Rock Mechanics \& Engineering, vol. 29, no. 1, pp. 2936-2942, 2010.

[7] D. Whyte, The overriding aspects of the design of geosynthetic-reinforced pile supported embankments, Proceedings of Contemporary Issues in Foundation Engineering. New York: ASCE publications, 2005.

[8] Railway institute of General technology, "The design and construction handbook of mixing piled foundation (machine mixing)", M.S. thesis, Tokyo: Railway Institute of General Technology, 2001.

[9] M. H. Zhao, Y. B. Deng, and M. H. Yang, "Calculation and Experimental Study on Pile-soil Stress Ratio of Macadam-column Composite Foundation under Load of Road Embankment”, Soil \& Rock Mechanics, vol. 30, no. 9, pp. 2623-2628, 2009.

[10] S. Y. Liu, Y. L. Yi, and Z. D. Zhu, "On-site Comparative Trial for Reinforcement of Highway Soft-soil Foundation with Bidirectional Mixing Pile”, Journal of Rock Mechanics \& Engineering, vol. 27, no. 11, pp. 2272-2280, 2008. 